International Journal of Linguistics, Literature and Culture
Available online at https://sloap.org/journals/index.php/ijllc/
Vol. 5, No. 1, January 2019, pages: 1 11
ISSN: 2455-8028
https://doi.org/10.21744/ijllc.v5n1.475

\title{
Exploring Textual Meaning in Chukwuemeka Ike's Sunset at Dawn: A Systemic Functional Approach
}

Innocent Sourou Koutchadé a André Cocou Datondji ${ }^{b}$ Amadou Salami ${ }^{\mathrm{c}}$

\section{Article history:}

Received: 9 July 2018

Accepted: 30 November 2018

Published: 11 December 2018

\section{Keywords:}

linguistic resources;

rheme;

sunset at dawn;

textual meaning;

theme;
The goal of this research work is to apply one of the three meanings developed by Halliday (1985), the grammar of textual meaning, to two extracts selected from Chukwuemeka's Sunset at Dawn (1976). This focus on textual meaning aims at unveiling the hidden linguistic resources or codes incorporated in the novel. It also aims at bringing out how the author of this novel has organized and established Themes to construct clauses in order to convey his message. Through a descriptive approach, the grammar of Textual meaning is studied in Chukwuemeka's Sunset at Dawn (1976). The qualitative descriptive method used in this article is supported by a quantitative method in using descriptive statistical analysis to calculate the percentage of the different fields. The study reveals that the Theme/Rheme structure is an essential component in the construction of a cohesive and coherent text. This has enabled us to assert that Sunset at Dawn by Chukwuemeka Ike is a well-written novel.

2455-8028 ${ }^{\circ}$ Copyright 2019. The Author. This is an open-access article under the CC BY-SA license (https://creativecommons.org/licenses/by-sa/4.0/) All rights reserved.

\section{Author correspondence:}

Innocent Sourou Koutchadé,

University of Abomey-Calavi, Republic of Benin

Email address: koutchade2@yahoo.fr

\section{Introduction}

The use of linguistic methods is a useful way of analyzing literary texts successfully since the reader must have an understanding of how the language functions and how it operates (Koutchadé 2016:299). The present study aims

a University of Abomey-Calavi, Republic of Benin

${ }^{\mathrm{b}}$ University of Abomey-Calavi, Republic of Benin

${ }^{\text {c }}$ University of Abomey-Calavi, Republic of Benin 
at unveiling the hidden linguistic resources or codes incorporated in Chukwuemeka Ike's Sunset at Dawn. In fact, Sunset at Dawn is a war novel between Nigeria and Biafra that has lasted thirty-months. The Biafrans are the one who has suffered more from the dire consequences of that war since it happens at Biafra land. Some thirty thousand Igbos have been brutally murdered and their property is looted and/or destroyed.

The goal of this study is to apply one of the three meanings developed Halliday (1985), i.e., the grammar of textual meaning, to two extracts selected from the Chukwuemeka's novel. As a matter of fact, this work clarifies how textual meaning makes sense within a language in literary texts, in general, and in Sunset at Dawn, in particular. This study helps to account for how the writer of Sunset at Dawn has organized and established Themes to construct clauses in order to convey his message. There are a set of studies in lexico-grammar which shed light on language use. It must be noted that the investigations in this field have been made and studied by scholars. Thus, Koutchade \& Loko (2016), have carried out an analysis of Chimamanda Ngozi Adichie's Americanah (2013) using the Systemic Functional Linguistics. They have used this theory to carry out a lexico-grammatical analysis of some selected extracts from the novel. From the analyses they have conducted, they have noticed that the systemic functional approach has been instrumental to unravel Chimamanda Ngozi Adichie's perception of the world-view, the social relationship language has played in the texts. They come to the conclusion that Chimamanda Ngozi Adichie, as all language users, has predicted the meanings that are likely to be exchanged and the language that is likely to be used when she has written Americanah.

Similarly, Koutchadé (2015), has dealt with Theme patterns, an aspect of the grammar of textual meaning whereby he has analyzed the language of Adetunji Ogundimu's A Silly Season through some selected extracts. The Theme patterns analysis in those extracts reveals a high use of topical unmarked and textual Themes. The analysis also reveals the presence of marked topical Themes, interpersonal Themes and marked dependent clauses as Themes in the extracts. He concludes that all these features have contributed to the understanding of Ogundimu's novel.

In addition, Koussouhon \& Mèhouénou (2016), have explored systemic functional grammar with an emphasis on the grammar of textual meaning in Akachi Ezeigbo's The Last of the Strong Ones. Their study helps to uncover the deep messages conveyed in the two selected extracts from the novel in which they have applied the grammar of Theme/Rheme in the process of describing their meanings about the experience, the social relationships between interactants as well as the rhetorical structure of their discourse. The ensuing discussion has revealed how Akachi Ezeigbo discloses the dialectical roles African women hold as individuals in society and as wives in their husband's houses.

As far as Yokossi (2013), is concerned, he has explored the Textual and Interpersonal Meanings in Ogundimu's The Insiders, A Silly Season and Behind the Mask, to disclose how the SFL theory can contribute to a better understanding of a writer's fiction. The mood analysis of the texts has revealed a huge number of declarations, which denotes that the participants mainly exchange information. This is suggestive of the strong desire of the writer to convey his message. The relatively important number of both interrogatives and imperatives has helped him realize the role relationships and power relations between the interactants in the fictional books. The choice in Modality (modalization and modulation) unveils the personalities of the participants in the extracts with a stress on their attitude, mood, on the basis of the roles they play in the fiction. Adjuncts, according to this researcher, not only exhibit the written mode of the texts but also help to the understanding of the interaction between the participants

\section{Materials and Methods}

According to Eggins (1994: 169), "textual meanings are meanings to do with the organization of the message itself." In other words, the textual meaning of language is an interpretation of language in its function as a message. At clause level, the textual meaning is concerned with how inter-clausal elements are organized to form unified whole texts that make meanings. It indicates the way the text is organized or structured. This specific type of meaning is realized through the Theme system of language (clause). The Theme system is in its turn, represented by the Thematic structure of the clause which comprises two major elements: Theme and Rheme. According to Halliday (1985: 39), Theme is the element which serves as "the starting point for the message; it is what the clause is going to be about". The Theme contains familiar or "given" information already mentioned somewhere in the text. In other words, the Theme is the element which comes first in the clause. So Theme identification is based on order.

Once the Theme is identified, the remainder of the clause belongs to the Rheme. Thus, the Rheme is the part of the speech in which the Theme is developed and since the Theme contains familiar information, the Rheme contains 
unfamiliar one. In short, the identification of Theme coincides with that of the Rheme, the Rheme being everything else.

Different types of elements of clause structure can be identified to be Theme:

- Topical Theme: this is an element of the clause to which a Transitivity role can be attached and which occurs in the first position in a clause. It can be marked (atypical) or unmarked (typical).

- Interpersonal Theme: a clause constituent is labeled interpersonal Theme when it could be assigned a Mood label (but not a Transitivity one) and occurs at the beginning of the clause. The constituents which can function as interpersonal Themes are the unfused Finite (in interrogative structures), and all the four categories of Modal Adjuncts: Mood, Polarity, Vocative, and Comment.

- Textual Theme: it realizes cohesion in relating clauses to their context (Dossoumou et al., (2018).

- Structural themes: they are relative pronouns or Wh-elements which bear neither the position of carrier nor that of topical. They usually occur after the clause boundary (Koussouhon \& Dossoumou, 2014).

- Multiple Theme: it is a Theme made up of two or more Themes, i.e., the topical Theme in a clause plus any textual or interpersonal Themes preceding it (Bloor \& Bloor, 2004).

As a matter of fact, the mixed (quantitative and qualitative) methods are adopted in the study. Two extracts have been selected from Chukwuemeka's Sunset at Dawn; they are analyzed through topical, textual, interpersonal, structural and multiple themes developed in the extracts. In order to facilitate their discussion, the findings of the analysis are summarized and distributed in a table. The following keys (Koussouhon \& Dossoumou, 2014), are used for the identification of each type: [Th:Utp] = Unmarked Topical Theme, [Th:Mtp] =Marked Topical Theme, [Th:strtp] =Structural Topical Theme, [Th:tx] =Textual Theme, [Th:str ] = Structural Theme, [Th:int] $=$ Interpersonal Theme, $[$ Th:mul $]=$ Multiple Theme

\section{Results and Discussions}

For the purpose of the analysis, texts are broken into clauses and patterns of Themes are identified (see the appendices). Then they have been counted and tabulated according to their categories. The frequency of Themetypes with their related percentages is summarized in table 1 below:

Table 1

Distribution of Theme types in the two selected extracts

\begin{tabular}{|c|c|c|c|c|c|}
\hline \multicolumn{2}{|c|}{ Theme types } & \multicolumn{2}{|c|}{ Extract 1} & \multicolumn{2}{|c|}{ Extract 2} \\
\hline & Unmarked & 121 & $75.15 \%$ & 161 & $76.67 \%$ \\
\hline \multirow[t]{2}{*}{ Topical } & Marked & 02 & $1.24 \%$ & 01 & $0.47 \%$ \\
\hline & Structural & 10 & $6.21 \%$ & 09 & $4.28 \%$ \\
\hline \multirow{2}{*}{\multicolumn{2}{|c|}{$\begin{array}{l}\text { Textual } \\
\text { Interpersonal }\end{array}$}} & 12 & $7.47 \%$ & 27 & $12.86 \%$ \\
\hline & & 04 & $2.48 \%$ & 00 & $00 \%$ \\
\hline \multicolumn{2}{|c|}{ Structural } & 11 & $6.88 \%$ & 12 & $5.71 \%$ \\
\hline \multicolumn{2}{|l|}{ Multiple } & 01 & $0.62 \%$ & 00 & $00 \%$ \\
\hline \multicolumn{2}{|c|}{ Total Themes } & 161 & $100 \%$ & 210 & $100 \%$ \\
\hline
\end{tabular}

The table above gives an account of the statistical distribution of theme types in the two selected extracts from Sunset at Dawn and the practical analysis carried out in those extracts reveals a predominance of unmarked topical themes in both extracts (i.e. $75.15 \%$ in extract 1 and $76.67 \%$ in extract 2 ). This indicates that the extracts about concrete actions carrying along material, physical and psychological deed. The important number of topical Themes also shows that clauses within them are made up with participants. The textual themes rank second in both extracts (7.47\% in extract 1 and $12.86 \%$ in extract 2 ) followed by structural themes $(6.88 \%$ in extract 1 and $5.71 \%$ in extract 2). Interpersonal and multiple themes rank last in the first extract respectively with $2.48 \%$ and $0.62 \%$ but they are absent in the second extract. This ranking is the key to open the door for a critical analysis of the two selected extracts.

Koutchadé, I. S., Datondji, A. C., \& Salami, A. (2018). Exploring textual meaning in Chukwuemeka Ike's Sunset at Dawn: a systemic functional approach. International Journal of Linguistics, Literature and Culture, 5(1), 1-11. https://doi.org/10.21744/ijllc.v5n1.475 


\section{Discussion and Interpretation of the Findings of the two Extracts}

\subsection{Critical Discussion of the Findings from Extract 1}

The theme identified in the extract shows an overall number of 161 themes. Out of this figure, one hundred and thirty-three $(133 ; 78.60 \%)$ is topicalized; these themes are unmarked, marked or structural. The same extract contains twelve $(12 ; 7.47 \%)$ textual themes, eleven $(11 ; 6.88 \%)$ structural themes, four $(04 ; 2.48 \%)$ interpersonal themes and one $(01 ; 0.62 \%)$ multiple theme. The investigation of Theme patterns in the first extract from Chukwuemeka's Sunset at Dawn, reveals the presence of topical and textual Themes in the identified clauses. It is noticed that topical Themes are predominant in the extract. This predominance suggests that, in all the clauses from the extract, there is at least a constituent in each clause to which a transitivity role such as Actor, Senser, Behaver or Circumstance is identified. Such a situation indicates that the extract reveals experiences (meanings about reality) shared by the participants (Chief Madukegbu Ukadike and Mazi Kanu) in the extract in particular and in the novel, to a large extent, in general.

Other Theme patterns studied in the first extract from the novel, Sunset at Dawn, are textual ones. These are elements which, occurring in the first position, do not express any interpersonal or experiential meaning but are playing an important cohesive role in relating the clauses to their situational context in the extract (Eggins, 1994:181) cited by Koutchadé \& Loko (2016:80). The rates of $7.47 \%$ and $6.88 \%$ for the textual theme and structural theme show that the writer has attached importance to the organization of his message by using a lot of conjunctions to make the story cohesive, and thus understandable. The presence of interpersonal Theme (2.48\%) denotes some short dialogues that occur in the extract between Chief Madukegbu Ukadike and Mazi Kanu, which starts with a town crier who delivers a message of the War Council to men and women of Obodo requiring them to donate food items to the Council: one big yam by every taxable male, five cassava tubers or one cup of garri by every woman and one tin of palm oil by every village. There is a little conversation between Mazi Kanu and Chief Madukegbu Ukadike concerning that issue. These food items are collected to feed soldiers, refugees, and other civil servants. As a matter of fact, the unmarked topical themes in clauses $\mathrm{n}^{\circ} 2,12,14,16$ and 32 indicate the presence of a local civil defense committee aiming at protecting Obodo people from further disastrous consequences resulting from the BiafranNigeran war. As it can be noticed, the whole story revolves around Dr. Amilo Kanu, his family and relations and Duke Bassey from Anang Province, Professor Emeka Ezenwa from Onitsha, Barrister Chike Ifeji and Dr. Osita. Biafran forces are ill-trained, ill-equipped, hurriedly assembled. By August, surprisingly while Nigerian troops from the Nsukka sector are slowly gaining grounds, Biafran forces gallantly capture Mid-West and proclaim it the Republic of Benin. Nigerian Federal Military Government now declares full-scale war on Biafra. In spite of all these, by late September 1967, there is an abortive coup by some highly placed Biafran army officers and civilians. The fate of Enugu seems to be uncertain since the first enemy mortar landed, and more continue to land. The ongoing war gives birth to some refugee camps which have welcomed some refugees. This can be noticed in clauses $\mathrm{n}^{\circ} 57,62,68$, 85 and 86. Roughly, this extract reveals some disastrous consequences of the Biafran-Nigerian war upon the people.

\subsection{Critical Discussion of the Findings from Extract 2}

As in the first extract, theme patterns have been identified in the second extract from the novel under study; and here a total number of two hundred and ten (210) have been identified. Out of this number, 171 (81.42\%) are topical and rank first, $27(12.86 \%)$ are textual themes and $12(5.71 \%)$ are structural themes. The conversation then shifts to Chief Madukegbu Ukadike (Chairman of the Local Council and Chairman of the Obodo War Council) and Dr. Amilo Kanu's wife, Fatima. In fact, Chief Madukegbu Ukadike comes to find out whether Fatima still receives any molestation of any kind from anybody in Obodo because of the marks on her face as Fatima is not a native of Obodo. But Fatima is not happy at all at being left there by her husband, Dr. Amilo Kanu. She doesn't know whether she should call it molestation, as there's hardly a day she goes out when she doesn't run into one incident or another. She thought her marks would make it clear that she not Igbo. They are angry when she can't reply in Igbo, as if there was a law that only speakers of the Igbo language can use the roads in Biafra! Many of the Biafran soldiers cannot speak English very well, that why they prefer communicating in the Igbo language. Chief Madukegbu Ukadike as Chairman of the local Council and Chairman of the Obodo War Council, reassures Fatima that he will see what he can do about that issue adding that he will find enough people who can speak English to replace the other ones.

But the only matter which annoys Fatima so much is their movement from Enugu to Obodo because she is not happy at all at being left there by her husband, Dr. Amilo Kanu. For instance, when Chief Madukegbu Ukadike 
would like to know whether Fatima can stay long at Obodo, her answer is promptly negative as in clauses $\mathrm{n}^{\circ} 165$, 166, 167, 168 and 169. Moreover, considering the clauses from $n^{\circ} 77$ down to $n^{\circ} 84$, it is clear that Fatima doesn't find herself comfortable at all. Even her father-in-law, Mazi Kanu is also uncomfortable as he finds it impossible to communicate with his son's wife because Igbo is the only Mazi Kanu's communicative language. And Fatima as far as she is concerned, she speaks Haussa and English as she is a literate Haussa woman. It is known very well that the wife Dr. Kanu has married is the kind with whom his father cannot converse without hiring an interpreter. The doctor wants her to stay at Obodo until the house he is putting up for her is ready. Is it not a big shame that Doctor should be the long- mouthed mouse which waits until labor pains set before building a nest for its use.

\section{Conclusion}

In a nutshell, this study has explored textual metafunction in Chukwuemeka Ike's Sunset at Dawn, using systemic functional linguistics. From the practical analysis, it has been revealed the predominant Theme type in the two selected extracts is topical. This result means that a great majority of the two extracts starting point features transitivity participants, whether circumstances participants, processes, or subject's participants. Based on the table and on the identification in the appendix, a general outcome reveals that the subject participants are predominant in all the two extracts. This indicates that Chukwuemeka Ike not only sets the structural organization of the conveyance of his message with more subjects as clause-initial elements but also wants his readers to pay more attention to the subjects first than any other elements. These subjects may vary in function. They may be actors, behavers, sensers, sayers etc. Textual Themes are also of a great importance in the extracts. The figures at this level show that the writer has made use of 39 linking clauses in the three selected extract from Chukwemeka's fictional art.

In the same way, structural Themes are also present in the selected extracts as they have their role to play. They represent $6.88 \%, 6.01 \%$, and $5.71 \%$ respectively in the first extract and in the second one. This suggests that Chukwuemeka Ike has made use of structural elements in his novel. This type of Themes gives an average of $5.46 \%$ in the three novels under study. This dissertation has studied the language of Sunset at Dawn a novel written by Chukwuemeka Ike following the theories of Systemic Functional Linguistics (SFL). It has explored systemic functional grammar with an emphasis on the textual meaning in Chukwuemeka's fictional literary arts.

Roughly, a linguistic investigation of the textual meaning in the novel reveals that the Theme/Rheme structure is an essential component in the construction of a cohesive and coherent text. Through the choice of some thematic elements, the spoken features are organized in such a way to make the readers know that the author makes use abundantly the unmarked Themes. They are defined in term of any element of the clause to which a Transitivity function can be assigned. All this has enabled us to assert that Sunset at Dawn by Chukwuemeka Ike is a well-written novel.

Conflict of interest statement and funding sources

The authors declared that they have no competing interest. The study was financed by personal funding.

Statement of authorship

The authors have a responsibility for the conception and design of the study. The authors have approved the final article.

Acknowledgments

The authors would like to thank the editorial team of IJLLC, for having accepted to publish the present manuscript.

Koutchadé, I. S., Datondji, A. C., \& Salami, A. (2018). Exploring textual meaning in Chukwuemeka Ike's Sunset at Dawn: a systemic functional approach. International Journal of Linguistics, Literature and Culture, 5(1), 1-11. https://doi.org/10.21744/ijllc.v5n1.475 


\section{References}

Bloor, M., \& Bloor, T. (2013). The practice of critical discourse analysis: An introduction. Routledge.

Chukwuemeka, I. (1976). Sunset at Dawn. Glasgow: Fontana/Collins.

Dossoumou, A. M., Mehouenou, M. S., \& Koukpossi, A. O. (2018). Appraising the impacts of cohesion and coherence in Benin SS3 EFL learners' writing productions. International Journal of Linguistics, Literature and Culture, 4(5), 41-54. https://doi.org/10.21744/ijllc.v4n5.293

Eggins, S. (1994). An introduction to systemic functional grammar. London: Pinter.

Eggins, S. (2004). Introduction to systemic functional linguistics. A\&C Black.

Halliday, M. A. (1985). Dimensions of discourse analysis: grammar. Handbook of discourse analysis, 2, 29-56.

Halliday, M. A. K., \& Hasan, R. (1985). Language, context andtext. Victoria: Deakin University Press.

Koussouhon, A. L., \& Koutchadé, I. (2013). Aspects of Texture in Wole Soyinka's 'Death in the Dawn'and 'In Memory of Segun Awolowo'. Particip'Action, 5(1), 121-135.

Koussouhon, L. A., \& Dossoumou, A. M. (2014). Lexico-Grammatical Analysis of Yellow-Yellow by Kaine Agary with a Focus on Experiential and Textual Meanings. Mediterranean Journal of Social Sciences, 5(23), 2430. http://dx.doi.org/10.5901/mjss.2014.v5n23p2430

Koussouhon, L. A., \& Tchibozo-Laine, I. (2016). Tenor and Interpersonal Meaning in Amma Darko's Fiction: A Feminist Approach. Studies in English Language Teaching, 4(4), 650. http://dx.doi.org/10.22158/selt.v4n4p650

Koussouhon, L. A., \& Tchibozo-Laine, I. (2016). Tenor and Interpersonal Meaning in Amma Darko's Fiction: A Feminist Approach. Studies in English Language Teaching, 4(4), 650.

Koussouhon, L. A., Akogbeto, P. C., Koutchade, I., \& Allagbe, A. A. (2016). Decoding the context of ideology in two extracts from a contemporary Ghanaian prose work. Littérature, Langues et Linguistique, (003).

Koussouhon, L., \& Mèhouénou, S. Exploring Textual Metafunction in Akachi Ezeigbo's The Last of the Strong Ones: A Gender-Based Analysis of Female Roles in Contemporary African Society.

Koutchadé, I. S. (2015). Thematic Structure and Foregrounding in Selected Extracts from Adetunji Ogundimu's A Silly Season. International Journal of English and Literature (IJEL), 5(4), 43-54.

Koutchade, I. S., \& Mehouenou, S. (2015). Male-Female Characters' Tenor of Discourse in Akachi Ezeigbo’s The Last of the Strong Ones. International Journal of Linguistics, 8(3), 167-182.

Mèhouénou, M. S. \& Koutchadé S. I. (2016). Linguistic Inclusiveness and Exclusiveness in Akachi Ezeigbo's House of Symbols and Children of the Eagle. In Research Journal of English Language and Literature. 4(3), 770-789.

Yokossi, D. T. (2018). Exploring the Interpersonal Meaning in two extracts from Chimamanda Ngozi Adichie's Purple Hibiscus and Chinua Achebe's Anthills of the Savannah: A Comparative Systemic Functional Linguistic Perspective. Journal of Educational and Social Research, 8(1), 59-70. 


\section{Biography of Authors}

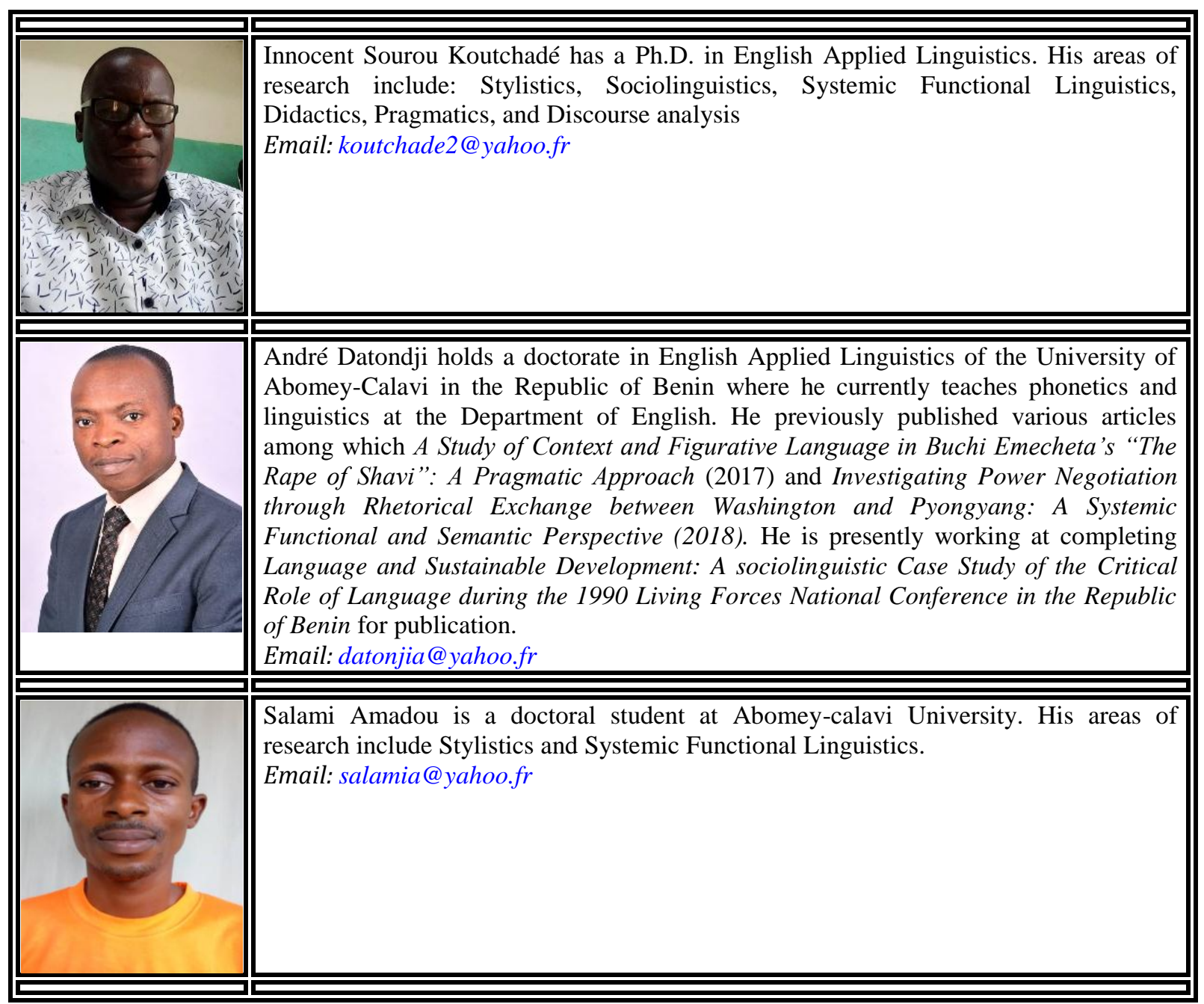

Koutchadé, I. S., Datondji, A. C., \& Salami, A. (2018). Exploring textual meaning in Chukwuemeka Ike's Sunset at Dawn: a systemic functional approach. International Journal of Linguistics, Literature and Culture, 5(1), 1-11. https://doi.org/10.21744/ijllc.v5n1.475 


\section{Appendices}

The following keys have been used in the present work:

$[$ Th:Utp] = Unmarked Topical Theme, $[$ Th:Mtp $]=$ Marked Topical Theme, $[$ Th:strtp $]=$ Structural Topical Theme, $[$ Th:tx $]=$ Textual Theme, $[$ Th:str ] =Structural Theme [Th:int $]=$ Interpersonal Theme[Th:mul] = Multiple Theme

\section{Theme Analysis in Extract 1}

1- 'What[Th:Utp] 2-council did he talk about?' Mazi Kanu [Th:Utp] 3-enquired as the town crier's ogene [Th:Utp] 4-grew silent and Aniche, the towncrier [Th:Utp], 5-moved towards the next village on his itinerary. Kanu [Th:Utp] 6-wore a warm, brown jumper over his woven wrapper. Fatima[Th:Utp], 7-his daughter-in-law had insisted that he[Th:Utp] 8-should always wear something over his wrapper, and[Th:tx] 9-had ordered some new jumpers for him. 'War Council,' replied Chief Madukegbu Ukadike[Th:Utp], 10-who[Th:strtp] was paying Mazi Kanu a visit. Both men[Th:Utp] 11-sat under a cola nut tree enjoying the cool evening breeze. Is [Th:int] 12-this a new council?' 'No[Th:tx] 13- I [Th:Utp] 14-prefer the name War Council to Local Civil Defense Committee. So [Th:tx] 15- I [Th:Utp] 16-have changed our name to Obodo War Council. Stops people[Th:Utp] 17-confusing us with the committee that [Th:strtp] 18-is the Church Committed. Also it[Th:Utp] 19-sounds better.'Mazi Kanu [Th:Utp] 20-replied with an anecdote: 'One itibolibo like me who[Th:Utp] 21-never as much as heard the school bell ringing was eating food one day in the company of those men whose heads [Th:Utp] 22-have split in two by too much learning. The learned men [Th:Utp] 23-kept speaking istafablushbulfa... and so[Th:mul] 24-on in English. As their conversation[Th:Utp] 25-in English changed on and on, itibolibo like me[Th:Utp] 26-told them lgbo: you[Th:Utp] 27-may speak whatever language you[Th:Utp] 28-like; the pieces[Th:Utp] 29-of meat in the soup are four and [Th:tx] 30-we[Th:Utp] 31-are four, one piece of meat for each of us! Likewise, call [Th:Utp] 32-it committee or council, every day the demands[Th:Utp] 33-will be the same - every male, one big yam, every woman, one cup of garri or five cassava tubers. Tell [Th:Utp] 34-me, those of you who [Th:strtp] 35-know what [Th:Utp] 36-is happening, will [Th:int] this thing ever come to an end?'

37-'Is [Th:int] there any story that [Th:Utp] 38-has no end?' asked[Th:Utp] 39-Ukadike stroking his beard. 'You [Th:Utp] 40-should thank your shi that[Th:str] 41-you [Th:Utp] 42-have the yams to give. What of those people who [Th:strtp] 43-have been driven out of their homes? I [Th:Utp] 44-am sure they [Th:Utp] 45-would be happy beyond words if they [Th:Utp] 46-were given back their homes and[Th:tx] 47-asked to donate one stick of yams or one bag of garri every day.' Bo, that one[Th:Utp] 48-has no comparison.' Mazi Kanu[Th:Utp] 49-used his finger to eject a bee which[Th:strtp] 50-floated on the top of his cup of wine after drinking itself to death, 'Each time I[Th:Mtp] 51-see a "riverju" the tears[Th:Utp] 52-begin to form in my eyes. How [Th:Utp] 53-can a man with a wife and[Th:tx] 54-children live in a school hall day in day out, with no compound of his own, waiting for gov'ment or the mission to bring food for his family. Who[Th:strtp] 55-was it saying in jest the other day that[Th:str] 56these overjus[Th:Utp] 57-have become gov'ment workers in their old age, being sent on transfer from their homes to riverju camps far from one riverju camp to another. I [Th:Utp] 58-told him to stop laughing, it[Th:Utp] 59-is not good to laugh at evil. You[Th:Utp] 60-know death is preferable to this kind of life. God[Th:Utp] 61-forbid that[Th:str] I [Th:Utp] 62-should ever be a riverju!' 'Thank your chi that[Th:str] 63-Nigerians [Th:Utp] 64changed their mind after Enugu, and [Th:tx] 65-went to Calabar and[Th:tx] 66-Onitsha instead of heading for Obodo as we[Th:Utp] 67-had feared. Who [Th:strtp] 68-knows in which refugee camp each one of us[Th:Utp] 69would have been today?' 'Our ancestors[Th:Utp] 70-cannot let such abomination come to pass with their eyes wide open. Whoever [Th:strtp] 71-says yes, his shi[Th:Utp] 72-will say yes; whoever[Th:strtp] 73-says no, his shi[Th:Utp] 74-will say no. God [Th:Utp] 75-forbid that[Th:str] 76-a person who[Th:strtp] 77-has eaten um of a plate ail his life[Th:Utp] 78-will suddenly find himself eating out of earthen pots.' 'I [Th:Utp] 79-hope every man[Th:Utp] 80-at Obodo will view the situation as seriously as you[Th:Utp] 81-do, Mazi,' Ukadike [Th:Utp] 82said. 'Perhaps it[Th:Utp] 83-is a good thing that[Th:strtp] 84-we[Th:Utp] 85-have a chance of seeing the suffering of refugees...' 'Evil[Th:Utp] 86-cannot be a good thing,' Mazi Kanu [Th:Utp] 87-interrupted 'I [Th:Utp] 88-know what I [Th:Utp] 89- am saying,' continued Ukadike [Th:Utp], 90-'Sometimes when the few of us who[Th:strtp] 91-have fought in world wars tell them people what to do, they[Th:Utp] 92-react as if somebody [Th:Utp] 93-oiled their cars into deafness. It[Th:Utp] 94-is only when they[Th:Utp] 95-see a refugee and[Th:tx] 96-his family[Th:Utp] 97-running out without even a mat on which to sleep, let[Th:Utp] 98-alone a wrapper with which to cover up, that[Th:str] 99-what you[Th:Utp] 100-tell them about gathering their important together for any 
eventuality means something.' 'Don't[Th:Utp] 101-blame anybody Idere. I[Th:Utp] 102-know you[Th:Utp] 103people have said it. Doctor's wife[Th:Utp] 104-still cries about some of the things she[Th:Utp] 105-left behind at Enugu, and[Th:tx] 106-has asked me to pack some of my things together to avoid the mistake they[Th:Utp] 107made. But[Th:tx] 108-tell[Th:Utp] me what [Th:Utp] 109-will a man like me pack? My yam barn? My palm trees? My lands? My household property? Our goats? Our chickens? Tell[Th:Utp] 110-me, what am[Th:int] 111-I to pack? After packing, will I[Th:Utp] 112-carry them on my head when[Th:Utp] 113-the time to run comes?' 'Why am[Th:int] 114-I arguing my voice hoarse,' Ukadike [Th:Utp] 115-asked, 'when I[Th:Utp] 116-know that [Th:str] 117-Doctor[Th:Utp] 118-will arrange your evacuation? What I [Th:Utp] 119-should request is that[Th:str] 120you[Th:Utp] squeeze on the tailboard when the time[Th:Utp] 121-comes, God forbid[Th:Utp]!' 122-It[Th:Utp] 123-'s better to wish that [Th:str] 124-such a time[Th:Utp] 125-never comes. As for Doctor, you[Th:Utp] 126think he[Th:Utp] 127-remembers that[Th:str] 128-his old parents and relatives[Th:Utp] 129-still exist on this side of the earth? May[Th:Utp] 130-he, now that[Th:str] 131-his wife[Th:Utp] 132-is living here, I[Th:Utp] 133may join the well-to-do in drinking hot soup!'

"Thank[Th:Utp] 134-you for mentioning Doctor's wife, I [Th:Utp] 135-nearly forgot that[Th:str] 136-I [Th:Utp] 137-came to see her, there[Th:Utp] 138-'s a bone sticking stubbornly in my throat which 1[Th:Utp] 139-'m sure Doctor[Th:Utp] can help me to remove. 140-That[Th:Utp] 141-'s why I [Th:Utp] 142-want to see his wife to find out when Doctor[Th:Utp] 143-is expected at Obodo or how I[Th:Utp] 144-could contact him where he[Th:Utp] 145-is now.' 'I[Th:Utp] 146-knew it [Th:Utp] 147-wasn't me you[Th:Utp] 148-came to see,' Mazi Kanu [Th:Utp], 149-protested, 'My mistake[Th:Utp] 150-is that [Th:str] 151-I [Th:Utp] 152-gave you my evening "special"; I [Th:Utp] 153-should have left you to drink proper whisky with Doctor's wife!' 'If I[Th:Utp] 154-come to see Doctor's wife, I[Th:Utp] 155-have also come to see you,' Ukadiwe[Th:Utp] 156-wriggled out grinning. After all, Doctor's wife[Th:Mtp] 157-is your wife.' 'A child[Th:Utp] 158-owns a goat only in name.' 'You[Th:Utp] 159-cannot liken a son's wife to the child's ownership of a goat,' Ukadike[Th:Utp] 160-disagreed. 'All right. I [Th:Utp] 161-agree.

Theme Analysis in Extract 2 (pp. 111 - 115)

'Good evening.' Fatima's tone [Th:Utp] 1-was not very inviting, and [Th:tx] 2-it certainly did not give any indication that[Th:str] 3-she [Th:Utp] 4-knew her caller from Adam. 'It[Th:Utp] 5-seems Madam has forgotten me. I [Th:Utp] 6-am Chief Madukegbu Ukadike Chairman of the Local Council and Chairman of the Obodo War Council' Ukadike Fidgeted with his medals before continuing. 'You[Th:Utp] 7-remember I[Th:Utp] 8-was the person who [Th:strtp] 9-ordered our Civil Defenders to return that machine they [Th:Utp] 10-seized from your car at the Afo checkpoint.' 'Pardon [Th:Utp] 11-me,' Fatima [Th:Utp] 12-apologized. 'Of course I [Th:Utp] 13remember you. Oh yes [Th:tx]. 14-Only I [Th:Utp] 15-didn't notice your medals. Ukadike took [Th:Utp] 16-a quick glance at his famous medals, and[Th:tx] 17-fidgeted with them before thrusting his hands behind him." I[Th:Utp] 18-'m ashamed that [Th:str] I[Th:Utp] 19-failed to recognize the man who [Th:strtp] 20-returned my projector to me,' continued Fatima [Th:Utp]. 21-'There [Th:Utp] 22-was nothing I [Th:Utp] 23-didn't do to explain to those men that [Th:str] 24-the projector [Th:Utp] 25-was nothing to fuss about, but[Th:tx] 26they[Th:Utp] 27-were certain it [Th:Utp] 28-was a transmitter far communicating with Lagos. 'But [Th:tx], 29Madam, do you [Th:Utp] 30-blame them? which[Th:Utp] 31-of them has seen the po... I[Th:Utp] 32-mean, something like that before?' Ukadike[Th:Utp] 33-knew that[Th:str] 34-even he[Th:Utp] 35-had not. He[Th:Utp] 36-could not even repeat the name of the machine without prompting. 'I [Th:Utp] 37-wouldn't have felt so annoyed if they[Th:Utp] 38-had admitted their ignorance,' Fatima[Th:Utp] 39-replied. 'One of them, who[Th:strtp] 40claimed he[Th:Utp] 41-had spent twenty years in Lagos, irritated me so much when he[Th:Utp] 42-went on to demonstrate how my projector[Th:Utp] 43-was used as a transmitter! And[Th:tx] 44-the others[Th:Utp] 45-were gullible enough to swallow the rubbish. 'Won't you [Th:Utp] 46-sit down, Madam?' Ukadike offered his chair, at the same time moving towards the chair Mazi Kanu [Th:Utp] 47-had vacated as soon as[Th:tx] 48-the couple[Th:Utp] 49-began to speak in a language which[Th:strtp] 50-meant nothing to him. 'I [Th:Utp] 51shouldn't really stay', replied Fatima[Th:Utp], 52-sitting down on the chair she[Th:Utp] 53-was offered. 'I[Th:Utp] 54-'m stinking after a spell of firewood cooking, and[Th:str] 55-I [Th:Utp] 56- ought to have a wash now that [Th:str] 57-my son[Th:Utp] 58-has slept. I [Th:Utp] 59-ran out for kerosene for my cooker, and[Th:str] the only way[Th:Utp] 60-to get my food cooked is to blow the firewood. We [Th:Utp] 61-are moving backwards!'Madam, as Chairman of the Obada War Council, I[Th:Utp] 62-'ve come to find out whether you

Koutchadé, I. S., Datondji, A. C., \& Salami, A. (2018). Exploring textual meaning in Chukwuemeka Ike's Sunset at Dawn: a systemic functional approach. International Journal of Linguistics, Literature and Culture, 5(1), 1-11. 
[Th:Utp] 63-still receive any molestation of any kind from anybody in Obada because of the marks on your face I[Th:Utp] 64-mean, because you[Th:Utp] 65-are not a native.' 'I[Th:Utp] 66-don't know whether I [Th:Utp] 67should call it molestation.' replied Fatima [Th:Utp] 68-rubbing her checks with bath hands as if to stroke the horizontal tribal marks on each cheek which[Th:strtp] 69-immediately marked her out as a stranger wherever she[Th:Utp] went, 70-'but[Th:tx] there[Th:Utp] 71-'s hardly a day I [Th:Utp] 72-go out when I [Th:Utp] 73don't run into one incident or another. I [Th:Utp] 74-thought my marks would make it clear that[Th:str] 75I[Th:Utp] 'm not lgbo. Yet[Th:tx] 76-people [Th:Utp] 77-will insist on speaking to me in Igbo. They[Th:Utp] 78are angry when I[Th:Utp] 79-can't reply in Igbo, as if there [Th:Utp] 80-was a law that[Th:str] 81-only speakers[Th:Utp] 82-of the Igbo language can use the roads in Biafra!' 'Many of our people [Th:Utp] 83-cannot understand English.' 'You[Th:Utp] 84-should remove such people from the checkpoints. They[Th:Utp] 85-merely irritate road users. 'I[Th:Utp] 86-'ll see what I[Th:Utp] 87-can do about that, Madam, if I [Th:Utp] 88-can find enough people who[Th:strtp] 89-can speak English to replace them ,' Why do you[Th:Utp] 90-need so many checkpoints anyway? enquired Fatima[Th:Utp]. 91-'Ah[Th:tx]! The price of liberty[Th:Utp] 92-is eternal vigilance!' cried Ukadike[Th:Utp 93-proudly smacking his be-medalled chest joyfully at remembering the slogan popularized by Radio Biafra[Th:Utp]. 94-'Stuff and nonsense!' Don't[Th:Utp] 95-say that[Th:str] 96-O[Th:Utp], 97-Madam. Did you[Th:Utp] 98-not hear of the white reverend father[Th:Utp] 99-carrying the coffin of a child in his car? When vigilant Civil Defenders[Th:Utp] 100-at Ndikelionwu checkpoint opened the coffin, they[Th:Utp] 101-found that[Th:str] 102-it[Th:Utp] 103-contained explosives which[Th:strtp] 104-were to be used in blowing up the Hotel Presidential. But[Th:tx] 105-for the vigilance of the men at the checkpoint...'Fatima [Th:Utp] 106interrupted him: 'We[Th:Utp] 107-heard that story before we [Th:Utp] 108-left Enugu. My husband[Th:Utp] 109checked on it and[Th:tx] 110-found that no such thing[Th:Utp] 111-ever happened!'But[Th:tx] 112-this newspaper[Th:Utp] 113-reported, protested Ukadike[Th:Utp]. 114-'This newspaper - 1[Th:Utp] 115-'ve forgotten the name of the newspaper. 'Anyway what of the woman who[Th:strtp] 116-was caught carrying a bomb inside her brassiere?'And .[Th:tx] 117-you[Th:Utp] 118-believe that?' 'In this war, there[Th:Utp] 119-'s nothing I[Th:Utp] 120-can't believe.' 'Stuff and nonsense! That[Th:Utp] 121-'s why one sheepish-looking man[Th:Utp] 122-at a checkpoint was scared to touch my toilet bag, even after I[Th:Utp] 123-had told him what it[Th:Utp] 124-was. He[Th:Utp] 125-actually retreated one or two steps as[Th:tx] 126-I[Th:Utp] 127-pulled the zip open to show him the contents of the bag; he[Th:Utp] 128-probably feared I[Th:Utp] 129-was connecting the fuse to activate an explosive! I[Th:Utp] 130-'m sure state security will be none the worse and[Th:tx] 131-motorists[Th:Utp] 132-will be relieved if most of the road blocks and [Th:str] 133-checkpoints [Th:Utp] 134-are dropped. 'Prevention [Th:Utp] 135-is better than cure)' observed Ukadike[Th:Utp] 136-rather weakly. He[Th:Utp] 137-was an advocate of checkpoints and[Th:tx] 138-was not pleased to see someone[Th:Utp] 139-try to demolish them. 'Admitted,' replied Fatima [Th:Utp]. 140-'But [Th:tx] 141-what do checkpoints [Th:Utp] 142-prevent? Did I [Th:Utp] 143-not hear that[Th:str] 144-you[Th:Utp] 145-discovered several dangerous weapons in a man's house in this town? How did those weapons[Th:Utp] 146-pass through your innumerable checkpoints? Checkpoints [Th:Utp] 147-are useless and [Th:tx] 148-irritating to motorists unless you [Th:Utp] 149-have trained intelligent people to man them.' 'I [Th:Utp] 150-agree with you there.' Ukadike [Th:Utp] 151-was glad that[Th:str] 152-Doctor's wife[Th:Utp] 153did not condemn checkpoints completely. 'Perhaps Madam[Th:Utp] 154-can help me to train our men for their work.' 'Me?' asked Fatima[Th:Utp]. 155-Without waiting for the reply, she[Th:Utp] went on: 'I[Th:Utp] 156-'m afraid not! Your people[Th:Utp] don't accept me and[Th:tx] I[Th:Utp] 157-don't want to have anything to do with them. In any case, I[Th:Mtp] 158-have no intention of staying on here one day longer than I[Th:Utp] 159have to. All[Th:Utp] 160-I [Th:Utp] 161-can say to my husband's parents and many others around me is "Kedu" or[Th:tx] 162-“Odinma”...' 'That[Th:Utp] 163-'s good,' interrupted Ukadike[Th:Utp], 164-smiling gleefully. 'No no [Th:tx]! 165-I[Th:Utp] 166-can't live that kind of life much longer. Imagine[Th:Utp] 167-me [Th:Utp] 168blowing my eyes out so as to cook with firewood, or eating meat smoked over the fire because I[Th:Utp] 169-can't use a fridge. My son[Th:Utp] 170-has been unable to understand why the pit latrine[Th:Utp] 171-hurriedly dug for us does not have a flush handle' 'The house Doctor[Th:Utp] 172-is building for you will soon be ready. I[Th:Utp] 173-am sure he[Th:Utp] 174-will install everything you [Th:Utp] 175-want there.' 'With the blockade on? Anyway, I[Th:Utp] 176-'ve told him I[Th:Utp] 177-'m not interested in his house. I[Th:Utp] 178-don't want any more of this village life in which I[Th:Utp] 179-do nothing but[Th:tx] 180-blow firewood and[Th:tx] 181-I [Th:Utp] 182-'am pestered by Civil Defenders. I[Th:Utp] 183-'ve given him a month to fit us in where he [Th:Utp] 184-lives at Umuahia. When that month[Th:Utp] 185-is up, you[Th:Utp] 186-won't see me back here any more.' 'I [Th:Utp] 187-will be sorry if you[Th:Utp] 188-leave us.' 'Save[Th:Utp] 189-that for somebody else,' Fatima[Th:Utp] 190-said, rising. '[[Th:Utp] 191-'m sure everybody here will be only too glad to see this Hausa 
woman [Th:Utp] 192-leave their village to item. I[Th:Utp] 193-'m afraid it [Th:Utp] 194-'s late and [Th:tx] 195the water for my bath must be getting cold. Thanks for your concern for my welfare.' 'Good night, Madam.' Chief Ukadike [Th:Utp] 196-heaved a sigh of relief as [Th:tx] 197-Fatima [Th:Utp] 198-moved to the rear of the compound where a space [Th:Utp] 199-had been fenced round for her use as a bathroom. Her fearlessness, her daredevil [Th:Utp] 200-attitude (to be more exact) stunned him. As [Th:tx] 201-she[Th:Utp] 202-trotred off in the short dancing steps characteristic of white girls or been to's*, Chef Ukadike [Th:Utp] 203-shrugged his shoulders. He [Th:Utp] 204-would not like to be Fatima's husband. She [Th:Utp] 205-was definitely the type of wife who[Th:strtp] 206-wore the trousers; he [Th:Utp] 207-was certain that [Th:str] 208-her chest [Th:Utp] 209would be a jungle of masculine hair! 'Nwata gbujie!' he [Th:Utp] 210-shouted Mari Kanu's salutatory name.

Koutchadé, I. S., Datondji, A. C., \& Salami, A. (2018). Exploring textual meaning in Chukwuemeka Ike's Sunset at Dawn: a systemic functional approach. International Journal of Linguistics, Literature and Culture, 5(1), 1-11. https://doi.org/10.21744/ijllc.v5n1.475 